\title{
Recurrent Laryngeal Hamartoma-An Unusual Cause of Apneic Spells: Case Report and Review of Literature
}

\author{
Anupama Satpathy ${ }^{1}$, Arjun Dasgupta ${ }^{2}$, Chirajit Dutta ${ }^{3}$, Nittala VK Mohan ${ }^{4}$
}

\begin{abstract}
Hamartomas are focal congenital malformations consisting of a focus of mature locally derived tissues with abnormal histological architecture. Laryngeal hamartomas are extremely rare with even $<50$ cases as well documented and reported in Indian literatures till now. Common symptoms associated with laryngeal hamartomas are stridor, dyspnea, hoarseness, and dysphagia. After endoscopic and radiological examination, excision of mass under video-endoscopic guidance remains the mainstay of treatment with a very good prognosis.

Keywords: Apnea, Hamartoma, Supraglottic mass.

International Journal of Head and Neck Surgery (2021): 10.5005/jp-journals-10001-1415
\end{abstract}

\section{INTRODUCTION}

Albrecht introduced the term "Hamartoma" in 1904 and distinguished between true neoplasms and tumor-like lesions. ${ }^{1}$ The term "Hamartoma" is derived from the Greek word "Hamartanein" which means "to go wrong". ${ }^{2}$ Hamartomas are characterized by the formation of tumor-like masses consisting of disorganized but matured specialized cells indigenous to the location where it is found. They grow along with and at the same rate as the organ from where they arise, unlike neoplastic lesions. They usually occur as developmental anomalies with aging in adults and are rarely encountered in the larynx. ${ }^{2,3}$ Presentations of this tumor-like mass vary as per the site and size of the tumor. Here, we report a case of a 61-year-old man presenting with apneic spells due to recurrent supraglottic laryngeal hamartoma obstructing the airway from nasopharynx to laryngeal inlet.

\section{Case Description}

A 61-year-old male patient visited our outpatient department with complaints of apneic spells at night, snoring difficulty in swallowing, cough which increases on taking liquid diet. No history of nasal blockage or any relevant predisposing factors of apnea was detected. The patient had a history of tracheostomy with laryngeal mass excision in the year 2000. The histopathological examination of the mass showed $2.5 \times 2 \mathrm{~cm}$ benign cystic hamartoma. At present, fiber optic laryngoscopy revealed a smooth conical mass arising from the right aryepiglottic fold and lateral pharyngeal wall with upward extension into the nasopharynx. The airway from the nasopharynx to the laryngeal inlet was moderately compromised by the mass. Axial section of the computed tomography scan showed a well-defined lobulated lesion in the supraglottic region with dense central amorphic calcification obstructing the laryngeal airway (Fig. 1). After doing the routine blood and other preoperative investigations, anesthetic clearance, he was immediately taken for an elective temporary tracheostomy to facilitate anesthesia followed by microlaryngoscopy and coablation-assisted laryngeal mass excision preserving all the laryngeal functions. Grossly, it was a broad base smooth-surfaced mass of $3.5 \times 3 \times 2 \mathrm{~cm}$, firm to hard in consistency, covered by skin ellipse (Fig. 2), and sent for histopathological examination. Histopathology report
${ }^{1-4}$ Department of ENT and Head Neck Surgery, Medica Superspecialty Hospital, Kolkata, West Bengal, India

Corresponding Author: Anupama Satpathy, Department of ENT and Head Neck Surgery, Medica Superspecialty Hospital, Kolkata, West Bengal, India, Phone: +91 9051732751, e-mail: dr.anupamasingh@ gmail.com

How to cite this article: Satpathy A, Dasgupta A, Dutta C, et al. Recurrent Laryngeal Hamartoma-An Unusual Cause of Apneic Spells: Case Report and Review of Literature. Int J Head Neck Surg 2021;12(2):83-85.

Source of support: Nil

Conflict of interest: None

was a polypoid tissue lined by skin, subepithelium showed fibrocollagenous tissue, benign cartilage, bony spicules, and areas of new bone formation, suggestive of the hamartomatous lesion (Fig. 3). He was decannulated and discharged the next day with strapping. On follow-up visit after 10 days, the patient was fine and the tracheostomy wound was almost healed.

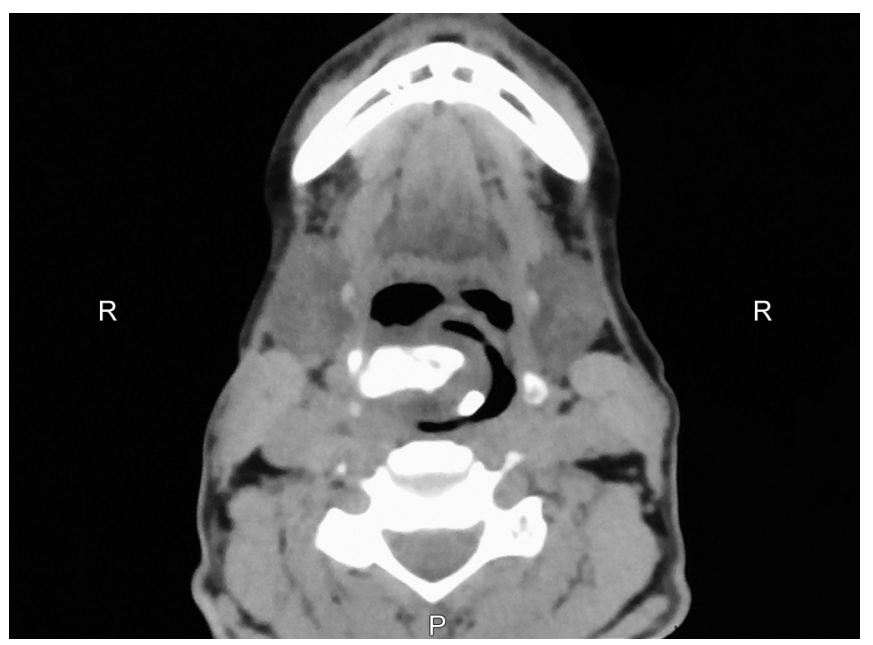

Fig. 1: Axial section computed tomography scan showing supraglottic mass with central calcification causing airway obstruction 


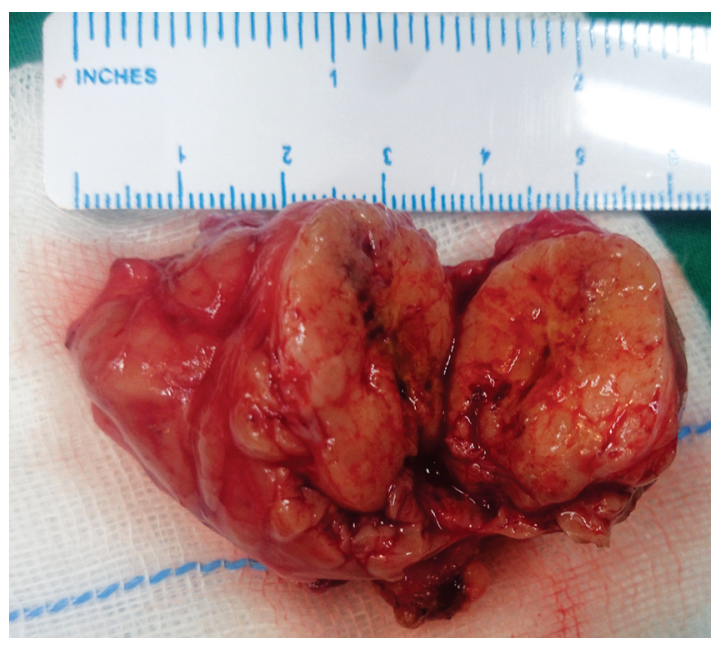

Fig. 2: Cut section showing smooth lobulated mass

\section{Discussion}

Apnea means a suspension of external breathing due to paucity of movement of muscles of inspiration. In adults, it usually occurs due to mechanical causes (strangulation/choking), drug-induced (opiate/tryptamine toxicity), or as a consequence of obstructive sleep apnea, neurological disease/trauma. Prolonged apnea can even lead to permanent brain damage due to lack of oxygenation in blood circulation. ${ }^{4}$ Here, in our patient, apneic spells were occurring due to a huge growth in supraglottis obscuring the airway from nasopharynx to laryngeal inlet.

Hamartoma is a tumor-like growth that usually occurs when an abnormal amount of normal cells with limited growth potential collect on healthy tissue. They are submucosal lesions with illdefined margins, mostly not encapsulated. They are characterized by the disorganized growth of mature tissue elements. Depending on tissue elements they can be "mesenchymal" - in mesodermal cells and lack epithelial components and "epithelial or glandular"which contain epithelial as well as mesodermal elements. Presentations of the mass are highly variable, can occur in infants as well as in adults, more common in males than in females. More commonly affected organs are the lungs, kidney, and intestine. They are uncommon in the head and neck region and are occasionally described in a sinonasal tract, nasopharynx, oropharynx, oral cavity, larynx, hypopharynx, cervical esophagus, parotid gland, trachea, parathyroid gland, and eye. ${ }^{5}$ Hamartoma in the larynx is very rare and commonly remains asymptomatic or presents with dyspnea, stridor, hoarseness, and dysphagia depending on its size and site. It is a developmental anomaly, benign in nature but locally destructive causing airway obstruction. ${ }^{6,7}$ Clinically differential diagnosis includes any benign and malignant lesions of the nasopharynx, hypopharynx, or larynx. A detailed history should be taken. Endoscopy, computerized tomography, or magnetic resonance imaging (MRI) plays a vital role in demonstrating the local extent of mass lesions and planning of treatment. Histopathology stands as a milestone to confirm the diagnosis. Microscopically hamartoma of the larynx is composed of mainly cartilage and fibromuscular tissues, fatty tissue and nerve elements are often present. Differential diagnosis includes choristomas, chondromas, teratomas, chondrometaplastic nodules, angiolipomas, and fibromas because of their histological resemblance. ${ }^{8}$ Choristomas are also benign tumors and can be separated from hamartomas by

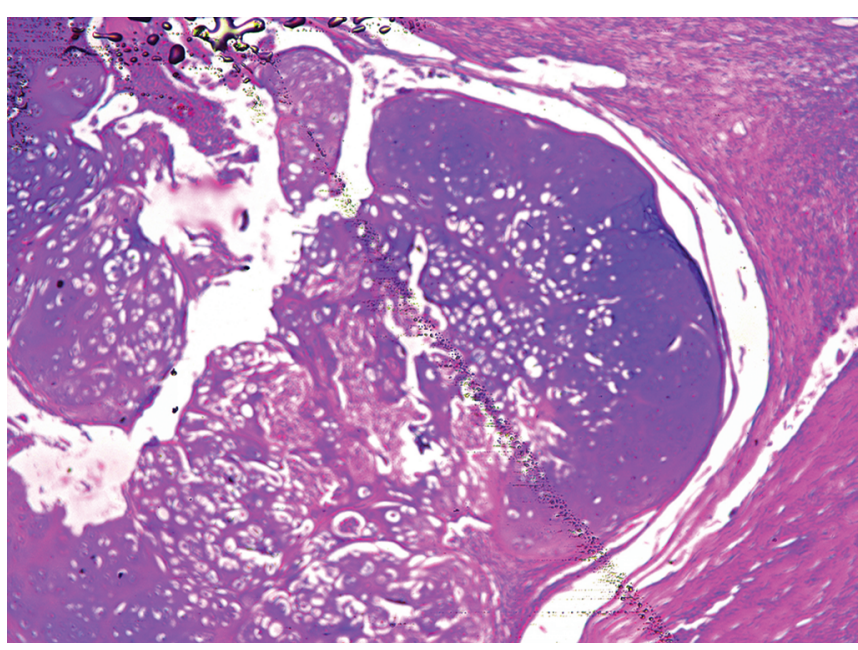

Fig. 3: Histopathological section showing features of hamartomatous lesion

being normal tissues in abnormal situations, whereas teratomas are foreign uncoordinated growths, actually a neoplasm. Chondromas are uncommon extremely slow-growing benign cartilaginous tumors arising from cartilaginous portions of bones, more common in skull base and paranasal sinuses. Treatment modalities include local surgical excision endoscopically using coablation, partial resection using $\mathrm{CO}_{2}$ laser or partial or total laryngectomies in case of larger lesions. The prognosis is good with little or no likelihood of recurrence. Recurrence is reported in $20 \%$ of cases which is usually associated with incomplete excision of the lesion. Very rare fatal outcomes have been reported. ${ }^{9,10}$

\section{Conclusion}

Laryngeal hamartomas are benign lesions usually managed conservatively with complete excision. Endoscopic examinations, computed tomography, and MRI play a vital role in defining the exact cause and management of apnea with the information of the site and extent of the lesion. Histopathology acts as a mainstay in diagnosis. Complete excision and regular follow-ups avoid any fatal outcomes and recurrence.

\section{References}

1. Albrecht E. Ueber hamartoma. Verh Dtsch Ges Pathol 1904;(7):153-157.

2. Kumar V, Abbas AK, Fausto N. Neoplasia Kumar V, Abbas AK, Fausto N. Robbins and Cotran pathologic basis of human disease. 7th ed., Philadelphia, PA: Elsevier-Saunders Publishing Company; 2005. p. 272.

3. Rinaldo A, Minnara G, Fischer C, et al. Hamartoma of the larynx: a critical review of the literature. Ann Otol Rhinol Laryngol 1998;107(3):264-267. DOI: 10.1177/000348949810700314.

4. Frumin MJ, Epstein RM, Cohen G. Apneic oxygenation in man. Anesthesiology 1959;20(6):789-798. DOI: 10.1097/00000542195911000-00007.

5. Fine ED, Dahmas $B$, Arnold JE. Laryngeal hamartoma: a rare congenital abnormality. Ann Otol Rhinol Laryngol 1995;104(2):87-89. DOI: 10.1177/000348949510400201.

6. Makitie A, Lehtonen $H$, Back L, et al. Hamartoma of the larynx: an unusual cause of dyspnea. Ann Otol Rhinol Laryngol 2003;112(10):841843. DOI: $10.1177 / 000348940311201003$.

7. Asal K, Ceylan A, Akyol G, et al. Hamartoma of the larynx: an unusual cause of upper airway obstruction. Eur Arch Otorhinolaryngol 2004;261(8):435-438. DOI: 10.1007/s00405-003-0712-x. 
8. Colon J, Jang D, Signore A, et al. Hamartoma of the larynx: a report of two cases. Laryngoscope 2011;121(S4):S128-S128. DOI: 10.1002/ lary.22005.

9. Triglia J, Preganelli A, Roman S, et al. A very rare large laryngeal Hamartoma in a 4 year old child: diagnosis and management. Int $J$
Paediatr Otorhinolaryngol Extra 2011;6(4):282-284. DOI: 10.1016/j. pedex.2011.01.004.

10. Mcgill $T$, Crockett $D$, Archer S. Hamartoma of the larynx: report of two cases and review of the literature. Int J Pediatr Otorhinolaryngol 1988;16(3):237-243. DOI: 10.1016/0165-5876(88)90035-3. 